\title{
Human giant larvae-1 promotes migration and invasion of malignant glioma cells by regulating $\mathbf{N}$-cadherin
}

\author{
YAN WANG ${ }^{1-3}$, YU ZHANG ${ }^{1,2}$, BEN SANG $^{1}$, XIANLONG ZHU ${ }^{1}$, RUTONG YU ${ }^{2,3}$ and XIUPING ZHOU ${ }^{2,3}$ \\ ${ }^{1}$ The Graduate School and ${ }^{2}$ Institute of Nervous System Diseases, Xuzhou Medical University; ${ }^{3}$ Department of Neurosurgery, \\ Affiliated Hospital of Xuzhou Medical University, Xuzhou, Jiangsu 221002, P.R. China
}

Received August 3, 2020; Accepted December 1, 2020

DOI: $10.3892 / 01.2021 .12428$

\begin{abstract}
Human giant larvae-1 (Hugl-1) is a human homologue of Drosophila tumor suppressor lethal (2)-giant larvae and has been reported to be involved in the development of human malignancies. Previous studies performed by our group demonstrated that Hugl-1 inhibits glioma cell proliferation in an intracranial model of nude mice. However, the exact molecular mechanisms underlying the participation of Hugl-1 in glioma invasion and migration, and in the depolarizing process remain largely unknown. Utilizing the U251-MG cells with stable expression of Hugl-1, the present study used wound healing, Transwell invasion and western blot assays to explore the role and specific mechanism of Hugl-1 in glioma invasion and migration. The results of the present study demonstrated that overexpression of Hugl-1 decreased cell-cell adhesion and increased cell-cell extracellular matrix adhesion. In addition, overexpression of Hugl-1 promoted pseudopodia formation, glioma cell migration and invasion. The molecular mechanism of action involved the negative regulation of $\mathrm{N}$-cadherin protein levels by Hugl-1. Overexpression or knockdown of $\mathrm{N}$-cadherin partially suppressed or enhanced the effects of Hugl-1 on glioma cell migration and invasion, respectively. Furthermore, Hugl-1 inhibited cell proliferation, while promoting cell migration, which suggests that it may serve a two-sided biological role in cellular processes. Taken together, these results suggest that Hugl-1 promotes the migration and invasion of malignant glioma cells by decreasing $\mathrm{N}$-cadherin expression. Thus, Hugl-1 may be applied in the development of targeted and personalized treatment.
\end{abstract}

Correspondence to: Professor Xiuping Zhou, Institute of Nervous System Diseases, Xuzhou Medical University, 84 West Huai-hai Road, Xuzhou, Jiangsu 221002, P.R. China E-mail: xpzhou@xzhmu.edu.cn

Professor Rutong Yu, Department of Neurosurgery, Affiliated Hospital of Xuzhou Medical University, 99 West Huai-hai Road, Xuzhou, Jiangsu 221002, P.R. China

E-mail: yu.rutong@163.com

Key words: glioma, Hugl-1, migration, invasion, N-cadherin

\section{Introduction}

Glioblastoma (GBM) is the most common malignant primary central nervous system tumor, with an average survival time of 12-15 months (1). The failure of conventional treatments is attributed to its highly invasive and diffusely infiltrative nature (2). Thus, the identification of novel therapeutic targets and strategies to improve the efficacy of existing forms of treatment is urgently required.

Cell polarity and intercellular adhesion play a key role in regulating normal tissue structure and function (3). The disruption of cell polarity and cell adhesion is usually associated with tumor formation (4). Lethal (2)-giant larvae ( $\mathrm{Lgl}$ ) is a cortical cytoskeletal protein, which was initially identified in Drosophila and exhibits notable effects in the establishment and maintenance of apical-basal epithelial polarity, asymmetric cell division, tissue integrity and cell proliferation (5). The human homologues of Lgl1 and Lgl2 are termed human giant larvae (Hugl)-1 and Hugl-2. Mutations that cause loss of function of $\mathrm{Lgl}$ have been demonstrated to result in tissue overgrowth and neoplastic tumor formation (6,7). The Hugl-1 protein shares $62.5 \%$ similarity with $\operatorname{Lgl}(8-10)$. A previous study indicated that hepatocellular carcinoma (HCC) contains frequent mutations of Hugl-1, whereas overexpression of HCC-derived aberrant Hugl-1 variants significantly promote HCC cell migration and invasion (11). In addition, Hugl-1 expression is downregulated in different types of human cancer, including colorectal cancer, melanoma, prostate cancer, breast cancer, endometrial cancer, lung cancer and esophageal carcinoma (12-15). Hugl-1 expression is positively associated with a higher survival rate in patients with pancreatic carcinoma, suggesting its use as a reliable prognostic marker (16). The majority of previous studies have focused on epithelial-derived tumors (11-15), thus the role of Hugl-1 in gliomas (glia-derived tumors) has not yet been fully elucidated. A previous study performed by our group has demonstrated that Hugl-1 protein levels decrease in human glioma tissues, whereas overexpression of Hugl-1 attenuates glioma cell proliferation in an intracranial model of nude mice; however, it does not affect glioma cell proliferation in vitro (17). As a regulator of cell polarity, Hugl-1 exhibits important properties that are closely associated with cell adhesion and cytoskeletal function and structure (18). However, the role of Hugl-1 in glioma migration and invasion has not yet been fully investigated. 
Cell surface adhesion molecules are the main mediators of cell-cell interactions, which are essential for tumor malignant biological behaviors. Reorganization of the cell cytoskeleton and alteration of cell-cell adhesion are required prior to cell migration $(19,20)$. These processes are mainly mediated by cadherin family members. It is reported that E-cadherin is essential for the normal migration of cranial neural crest cells in vivo, while P-cadherin, also known as placental cadherin, is associated with malignant invasion of esophageal squamous cells (21-24). In most tumors, N-cadherin expression is often upregulated and can be used as a promoter of tumor invasion $(25,26)$. N-cadherin expression in epithelial cells can induce morphological changes of fibroblast phenotype and orchestrate cell-cell communication during cell movement (27). N-cadherin is also known as an epithelial-to-mesenchymal transition marker and exhibits several functions according to the cell environment that can promote adhesion or induce migration $(28,29)$. However, increasing evidence suggests that $\mathrm{N}$-cadherin exhibits tumor-inhibitory roles in non-epithelial derived neoplasms, such as osteosarcoma and glioma $(27,30)$. Thus, the functions of $\mathrm{N}$-cadherin may be tumor-type specific (27).

The present study aimed to investigate the role and molecular mechanism of Hugl-1 on the motility of malignant glioma cells.

\section{Materials and methods}

Cell culture. The U251-MG glioma cell line was purchased from the Shanghai Cell Bank, Type Culture Collection Committee, Chinese Academy of Sciences. Cells were maintained in DMEM/F-12 media (Gibco; Thermo Fisher Scientific, Inc.) supplemented with $10 \%$ fetal bovine serum (FBS; Biological Industries), at $37^{\circ} \mathrm{C}$ in $5 \% \mathrm{CO}_{2}$.

Stable transfection of Hugl-1 into U251-MG cells. The pEGFP-C1 vector alone or the pEGFP-C1-Hugl-1 construct (provided by Professor Zhengjun Chen, Shanghai Institute of Biochemistry and Cell Biology, Chinese Academy of Sciences) was transfected into U251-MG cells (GFP-Vector or GFP-Hugl-1 cells, respectively) using Lipofectamine ${ }^{\circledR} 2000$ (Invitrogen; Thermo Fisher Scientific, Inc.), according to the manufacturer's instructions. Briefly, $9 \mu$ l Lipofectamine ${ }^{\circledR} 2000$ and $3 \mu \mathrm{g}$ of the Hugl-1 expression plasmid were added to $1 \mathrm{ml}$ Opti-MEM (Invitrogen; Thermo Fisher Scientific, Inc.) and incubated for $10 \mathrm{~min}$ at room temperature. The plasmid and Lipofectamine were mixed together and incubated for $30 \mathrm{~min}$ before adding them to the U251-MG cells. The transfectants were subsequently selected using G418 $(1,200 \mu \mathrm{g} / \mathrm{ml})$, and single-cell clones were obtained following 3-4 weeks of growth for expansion. The G418-resistant cells were used for subsequent experiments. DsRed-C1 or DsRed-N-cadherin plasmids were kindly provided by the Laboratory of Cell Biology of Northeast Normal University (Changchun, China). DsRed-C1 or DsRed-N-cadherin plasmids were transfected into Hugl-1 overexpressing U251-MG cells. The specific transfection procedure was the same as that of Hugl-1.

Digestion assay. Cultured GFP-Vector or GFP-Hugl-1 cells were digested with trypsin simultaneously (Gibco; Thermo Fisher Scientific, Inc.). Briefly, cells were digested with trypsin at room temperature for $8 \mathrm{~min}$ and observed at designated time points $(0,2,4$ and $8 \mathrm{~min})$ under an inverted light microscope during trypsinization at x200 magnification (Olympus Corporation; IX71).

Attachment assay. The attachment assay was performed using 12 -well plates. The cell suspension was added into the plates and cell images were obtained at 3, 6, 9 and $24 \mathrm{~h}$ using an inverted light microscope at x400 magnification (Olympus Corporation; IX71).

Wound healing assay. Cell migration was assessed via the wound healing assay, as previously described (31). Briefly, cells were seeded into 6 -well plates and cultured until they reached $\sim 80 \%$ confluence. The cell monolayers were scratched using a $10 \mu 1$ sterile pipette tip. Cells were subsequently washed twice with PBS to remove floating cells and serum-free DMEM/F-12 medium (Gibco; Thermo Fisher Scientific, Inc.) was added. Cell wound healing was observed at 0,24 or $48 \mathrm{~h}$ using an inverted light microscope at x200 magnification (Olympus Corporation; IX71).

Transwell invasion assay. The cell invasion assay was performed as previously described (31). Briefly, Transwell membranes were precoated with DMEM-diluted Matrigel ${ }^{\circledR}$ (BD Biosciences) for $3 \mathrm{~h}$ at $37^{\circ} \mathrm{C}$. Cells $\left(2 \times 10^{4}\right)$ were plated in the upper chambers of Transwell plates in $200 \mu 1$ serum-free culture DMEM/F-12 medium (Gibco; Thermo Fisher Scientific, Inc.). A total of $500 \mu \mathrm{l}$ DMEM/F-12 medium supplemented with $10 \%$ FBS was plated in the lower chambers. Following incubation at room temperature for $24 \mathrm{~h}$, the invasive cells were fixed in methanol for $15 \mathrm{~min}$ at room temperature and subsequently stained for $15 \mathrm{~min}$ at room temperature with $0.1 \%$ crystal violet. Invasive cells were viewed and counted under an inverted light microscope at x200 magnification (Olympus Corporation; IX71).

Western blotting. U251-MG cells were lysed with RIPA lysis buffer (50 mM Tris- $\mathrm{HCl}, 150 \mathrm{mM} \mathrm{NaCl}, 0.5 \%$ sodium deoxycholate and $0.1 \%$ SDS) supplemented with protease inhibitor cocktail, and total proteins were quantified using a BCA kit (Beyotime Institute of Biotechnology) according to the manufacturer's protocol. Western blotting was performed as previously described (32). Briefly, equal amounts of protein ( $20 \mu \mathrm{g} /$ lane) were separated by SDS-PAGE on 8 or $10 \%$ gels, transferred onto polyvinylidene fluoride membranes and blocked using 3\% BSA (Sangon Biotech Co., Ltd.) for $2 \mathrm{~h}$ at room temperature. The membranes were then incubated with primary antibodies against Hugl-1 (1:500) [kindly gifted by Dr ZG Luo from the Institute of Neuroscience, Shanghai Institutes for Biological Sciences, Chinese Academy of Sciences (33)], N-cadherin (1:2,000; cat. no. ab76011; Abcam), $\beta$-catenin (1:5,000; cat. no. ab32572; Abcam), integrin $\beta 1$ (1:1,000; cat. no. ab134179; Abcam) and $\beta$-actin $(1: 1,000$; cat. no. MABT523; EMD Millipore). Following the primary antibody incubation at $4{ }^{\circ} \mathrm{C}$ overnight, membranes were probed with HRP-labelled goat anti-rabbit or anti-mouse IgG secondary antibodies (1:4,000; cat. nos. sc2004 and sc2005; Santa Cruz Biotechnology, Inc.) at room temperature for $2 \mathrm{~h}$. The signal was detected using the Pierce ECL Plus Western 
Blotting Substrate (Pierce; Thermo Fisher Scientific, Inc.) and exposed to ChemiDoc Touch (Bio-Rad Laboratories, Inc.). Finally, gray analysis was performed using ImageJ $1.48 \mathrm{~V}$ (National Institutes of Health) to compare the level of each protein.

Phalloidin staining. U251-MG cells were incubated for $24 \mathrm{~h}$ at $37^{\circ} \mathrm{C}$ and cultured in DMEM/F-12 medium supplemented with $10 \% \mathrm{FBS}$ for $30 \mathrm{~min}$ at $37^{\circ} \mathrm{C}$. Subsequently, cells were fixed with $4 \%$ paraformaldehyde for $10 \mathrm{~min}$ at room temperature, washed twice with PBS, and $0.5 \%$ Triton X-100 was added for $5 \mathrm{~min}$ at room temperature. Finally, $200 \mu \mathrm{l}$ of the diluted phalloidin (cat. no. 94072; Sigma-Aldrich; Merck KGaA) was added and incubated at room temperature in the dark for $30 \mathrm{~min}$. Actin filaments were observed using an inverted fluorescence microscope at $\mathrm{x} 400$ magnification (Olympus Corporation; IX71).

Statistical analysis. Statistical analysis was performed using SPSS 13.0 software (SPSS, Inc.). All experiments were performed in triplicate and data are presented as the mean \pm standard error of the mean. Student's unpaired t-test was used to compare differences between two groups, while one-way AVONA followed by Tukey's post hoc test were used to compare differences between multiple groups. $\mathrm{P}<0.05$ was considered to indicate a statistically significant difference.

\section{Results}

Effects of Hugl-1 on cell adhesive activity. It has been demonstrated that Hugl-1 protein expression is downregulated in human glioma tissues compared with normal brain tissues (17). Given that Hugl-1 acts as a tumor suppressor in several human tumors, and its expressed at low levels in gliomas, the effect of Hugl-1 downregulation on this basis may be negligible. In addition, we detected six different glioma cell lines in the previous study and demonstrated that Hugl-1 protein expression was extremely low in U251-MG cells (17). Thus, to investigate the role of Hugl-1 in glioma, stable GFP-Hugl-1 overexpression was established in U251-MG glioma cells, and constitutive expression was assessed via western blotting (Fig. 1A and B). Due to the high molecular weight of Hugl-1 (115 kDa) (13), the molecular weight of GFP-Hugl-1 fusing protein was $141 \mathrm{kDa}(115 \mathrm{kDa}+26 \mathrm{kDa})$, which caused weaker GFP signaling in the GFP-Hugl-1 group compared with the GFP group. To determine the difference in the adhesive ability between the GFP-Hugl-1 and GFP groups, cells were trypsinized, and the results demonstrated that Hugl-1 overexpressing cells retracted more slowly compared with the GFP control cells (Fig. 1C), suggesting a better cell-extracellular matrix adhesive ability. Conversely, Hugl-1 overexpressing cells extended pseudopodia faster than GFP cells following plating (Fig. 1D). Notably, GFP cells formed cell aggregates unlike Hugl-1 overexpressing cells (Fig. 1D, black arrow), suggesting that upregulation of Hugl-1 decreases cell-cell adhesive activity. The cells presented in Fig. 1D exhibited complete roundness and good refraction, indicating that the cells were healthy. In addition, the digested cells were placed in a culture dish and gradually expanded.
$\mathrm{N}$-cadherin is a member of the calcium-dependent adhesion molecule family, which mediates adhesion between homotypic cells (34). Thus, $\mathrm{N}$-cadherin protein expression was detected at 3,6 and $24 \mathrm{~h}$ following plating. The results demonstrated that $\mathrm{N}$-cadherin expression was lower in Hugl-1 overexpressing cells compared with GFP cells at 3 and $6 \mathrm{~h}$ following plating (Fig. 1E and F).

Previous studies have demonstrated that adhesion molecules play an important role in the early stage of cell adhesion $(35,36)$, which gradually decreases overtime (37). In the present study, no significant difference was observed in $\mathrm{N}$-cadherin expression between the two groups $24 \mathrm{~h}$ after plating. Taken together, these results suggest that overexpression of Hugl-1 decreases cell-cell adhesion, while increasing cell-extracellular matrix adhesion by regulating $\mathrm{N}$-cadherin expression.

Hugl-1 accelerates cytoskeletal remodeling. To fully characterize the intercellular adhesion defects observed in Hugl-1 overexpressing cells, the intracellular organization of the cytoskeleton was assessed. Cells were incubated for $24 \mathrm{~h}$ and cultured in media supplemented with $10 \%$ FBS for $30 \mathrm{~min}$. Subsequently, cells were stained with phalloidin-conjugated actin to assess actin reassembling. The results demonstrated that Hugl-1 overexpressing cells expanded their lamellipodia earlier, which contained concentrated F-actin, and stretched faster than GFP cells (Fig. 2A). Previous studies have established $\beta$-catenin as a promoter signal, which is not only a key transcription factor in the Wnt signaling pathway but also a structural adaptor between cadherin and actin skeleton during cell adhesion $(38,39)$. The present study hypothesized that $\beta$-catenin may mediate cytoskeleton remodeling by overexpressing Hugl-1. The results of the present study demonstrated that $\beta$-catenin expression decreased in Hugl-1 overexpressing cells, while the expression levels of integrin $\beta 1$, another important molecule involved in cytoskeleton remodeling and adhesion (40), remained unchanged (Fig. 2B and C). Collectively, these results suggest that Hugl-1 may accelerate cell cytoskeleton reorganization by regulating the $\mathrm{N}$-cadherin- $\beta$-catenin complex.

Hugl-1 promotes the migration and invasion of glioma cells. The effect of overexpressing Hugl-1 on the migration of glioma cells was assessed via the wound healing assay. The results demonstrated that Hugl-1 overexpressing glioma cells exhibited faster wound healing than GFP cells after $48 \mathrm{~h}$ (Fig. 3A and B), whereby the number of migratory cells significantly increased to $30 \pm 7 \%$ ( $\mathrm{P}<0.01$; Fig. $3 \mathrm{~A}$ and $\mathrm{B}$ ). In addition, the effect of overexpressing Hugl-1 on the invasion of glioma cells was assessed via the Transwell assay. The results demonstrated that the number of invasive cells significantly increased to $139 \pm 5 \%$ following overexpression of Hugl-1 $(\mathrm{P}<0.01$; Fig. $3 \mathrm{C}$ and $\mathrm{D})$, which confirms that Hugl-1 promotes the invasive ability of U251-MG cells.

$N$-cadherin partially mediates the effects of Hugl-1 expression on glioma cell migration. $\mathrm{N}$-cadherin plays a key role in regulating cell polarity and motility (27). Based on the results presented in Fig. 1E, whether N-cadherin mediates the effects of Hugl-1 expression on glioma cell migration 
A

GFP-Vector
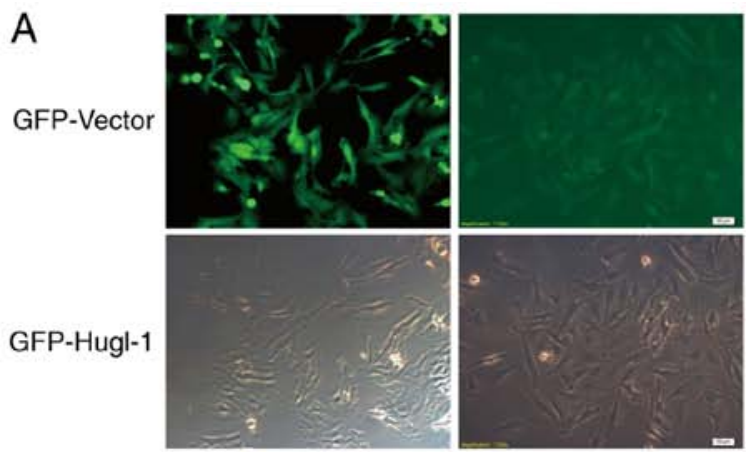

C

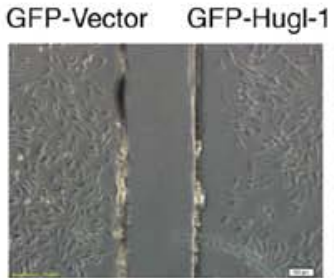

$3 \mathrm{~h}$
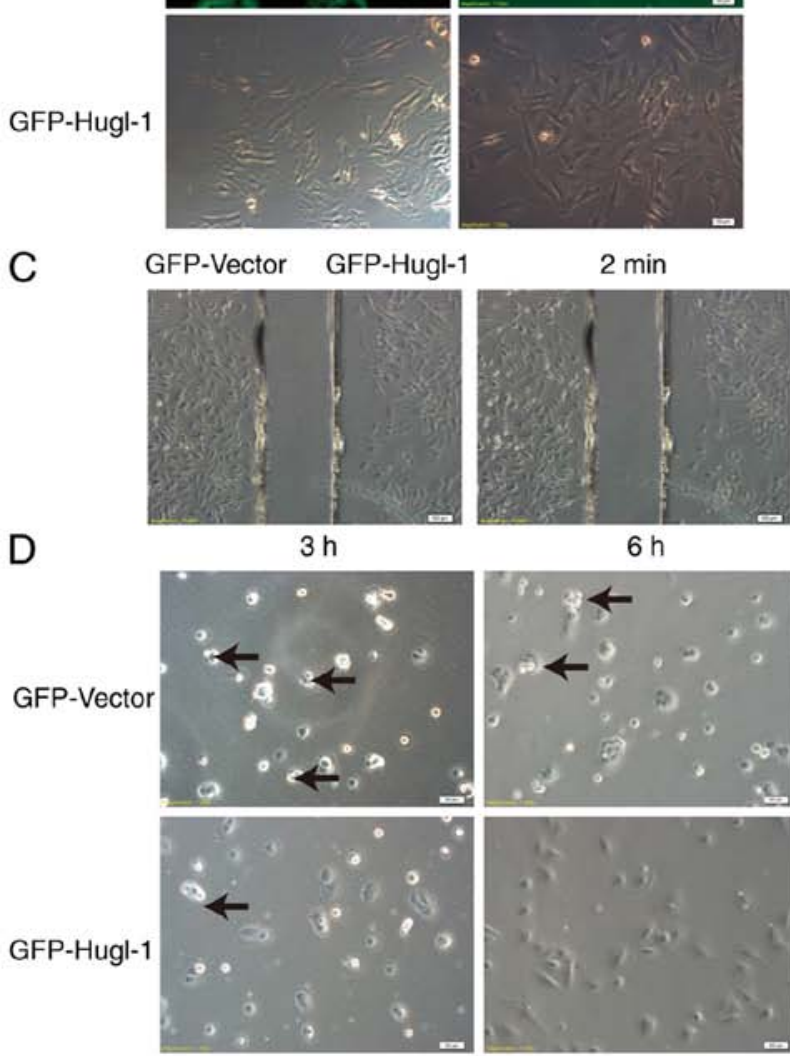

$6 \mathrm{~h}$
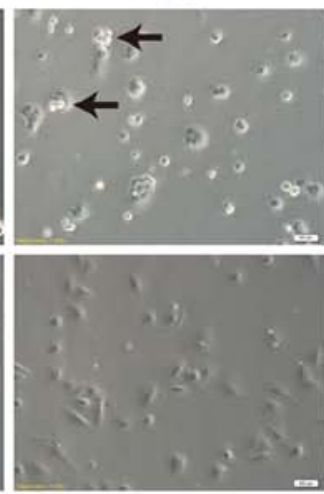

E

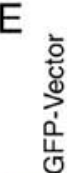

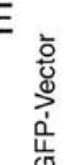

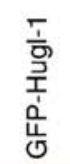

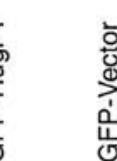

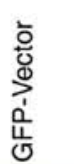
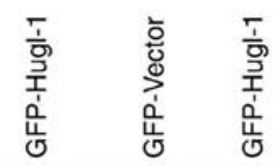
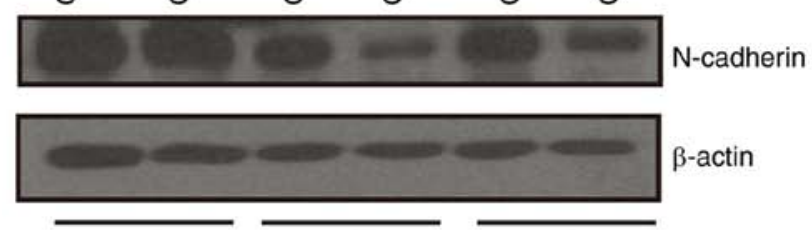

$24 \mathrm{~h}$

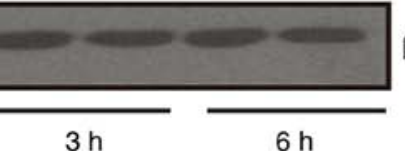

$6 \mathrm{~h}$
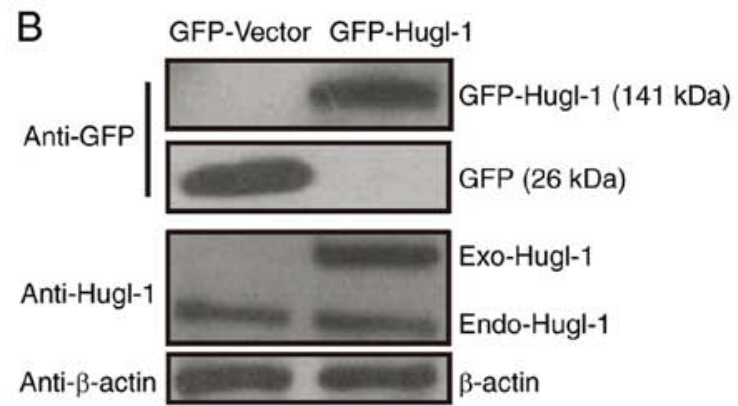

$4 \mathrm{~min}$

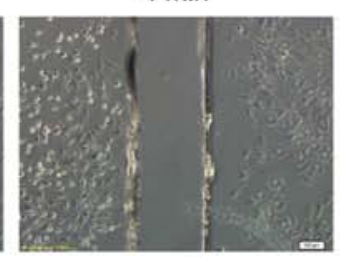

$9 \mathrm{~h}$
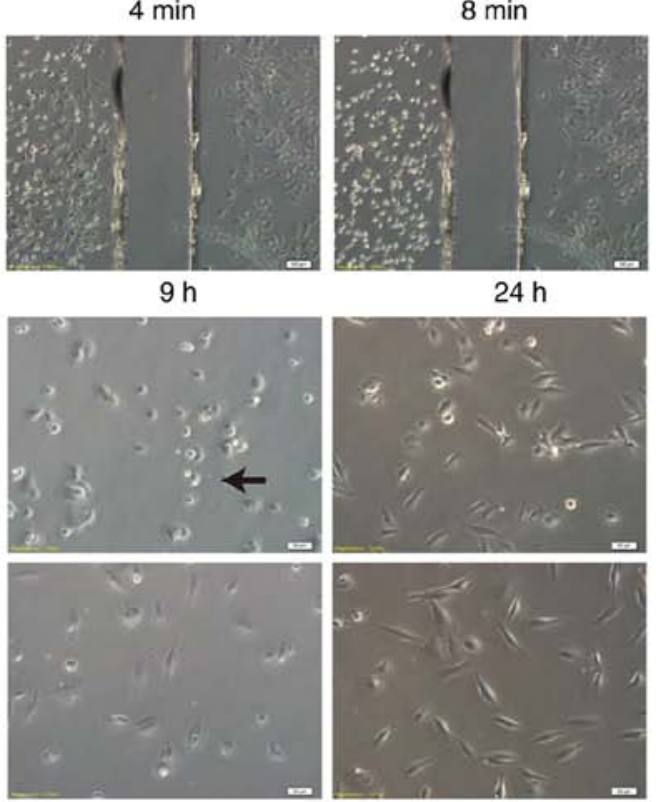

$24 \mathrm{~h}$

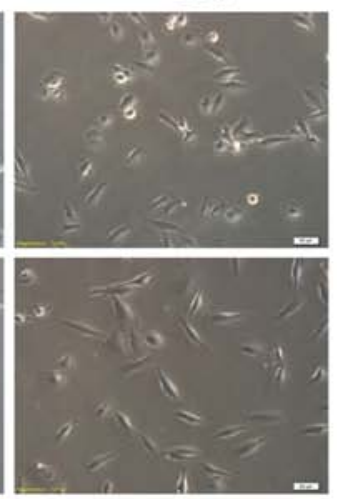

F $\begin{array}{r}\square \text { GFP-Vector } \\ \text { GFP-Hug-1 }\end{array}$

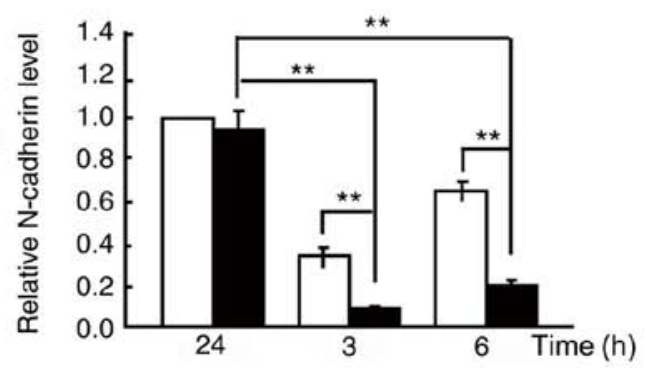

Figure 1. Hugl-1 affects cell adhesion. (A) GFP-Hugl-1 or GFP-Vector plasmids were transfected into U251-MG glioma cells, followed by G418 selection. The transfection efficiency was assessed via GFP fluorescence (scale bar, $50 \mu \mathrm{m}$ ). (B) Western blot analysis was performed to detect Hugl-1 protein expression. (C) Representative digital images obtained at 0,2,4 and 8 min during trypsinization (scale bar, $100 \mu \mathrm{m}$ ). (D) Representative digital images obtained at 3,6, 9 and $24 \mathrm{~h}$ following plating. Black arrowheads indicate the cell aggregates (scale bar, $50 \mu \mathrm{m}$ ). (E) N-cadherin protein levels were detected at 3,6 and $24 \mathrm{~h}$ following cell attachment. (F) Quantification results of (E). ${ }^{* *} \mathrm{P}<0.01$. Hugl-1, human giant larvae-1; GFP, green fluorescent protein.

was subsequently assessed. $\mathrm{N}$-cadherin was overexpressed in GFP and Hugl-1 overexpressing cells (Fig. 4A), and the results demonstrated that upregulation of Hugl-1 promoted cell migration, the effects of which were reversed following overexpression of N-cadherin (Fig. 4B and E).

Generally, the exogenous protein level is higher than that of the endogenous level. However, considering the high molecular weight of GFP-Hugl-1 (141 kDa) and N-cadherin (127 kDa), and the relatively low transit transfection efficiency $(12,13)$, the exogenous protein level was lower than the endogenous level in the present study (Fig. 4A). Notably, the induction effect of Hugl-1 on glioma cell migration was partially abolished following overexpression of $\mathrm{N}$-cadherin, compared with that of the Hugl-1 overexpressing cells (Fig. 4B and E). Conversely, $\mathrm{N}$-cadherin knockdown promoted cell migration, and the effects were similar to those noted in the Hugl-1 overexpressing cells (Fig. 4C, D and F). Furthermore, the increased migratory ability induced by Hugl-1 upregulation was significantly enhanced following downregulation of $\mathrm{N}$-cadherin in glioma cells (Fig. 4D and F). Taken together, these results suggest that 
A
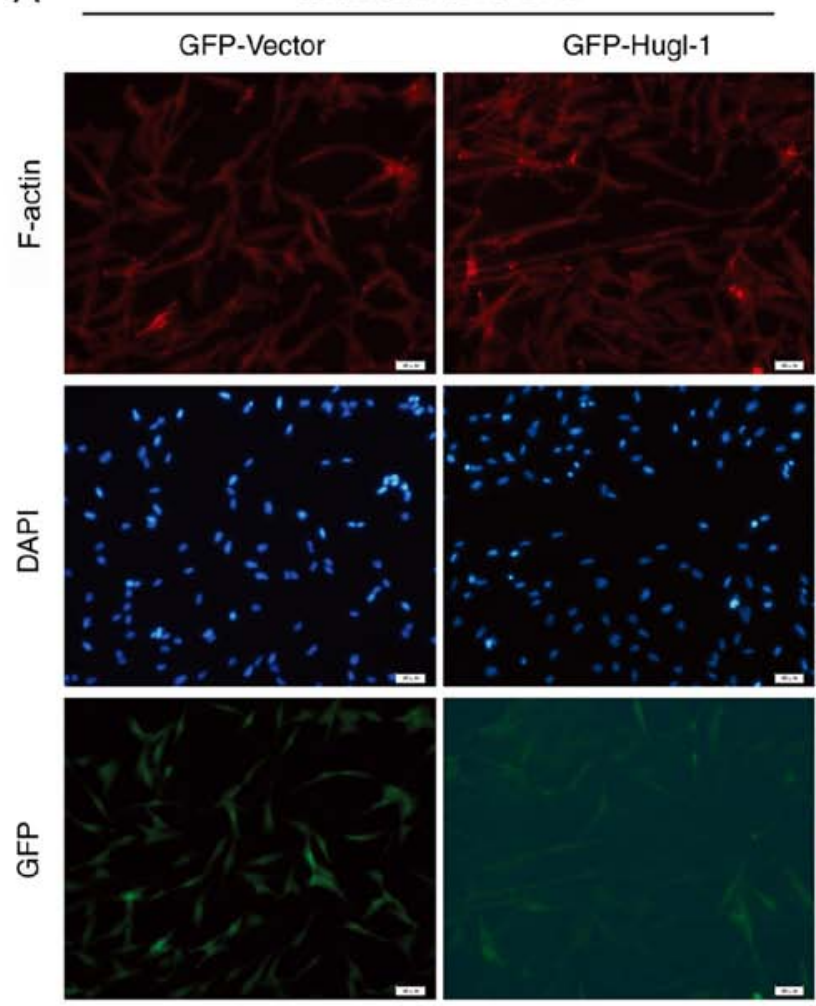

B

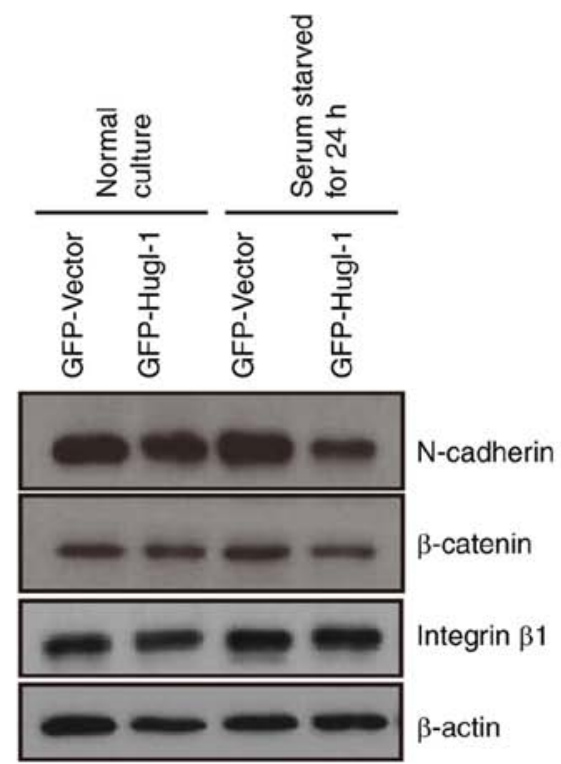

GFP-Hugl-1
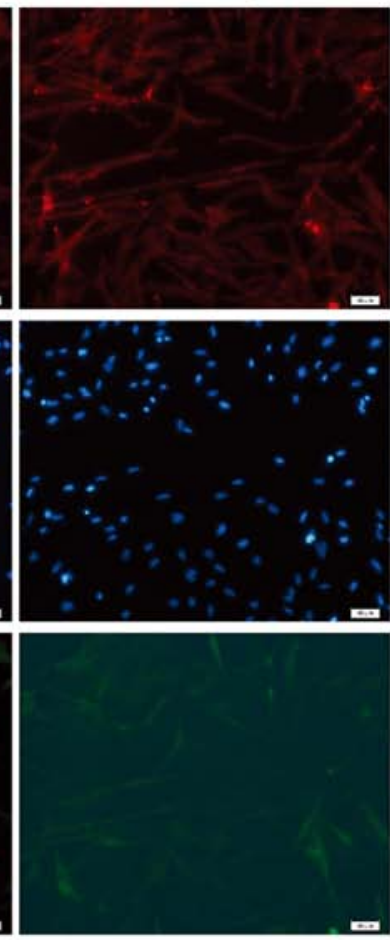

$-$
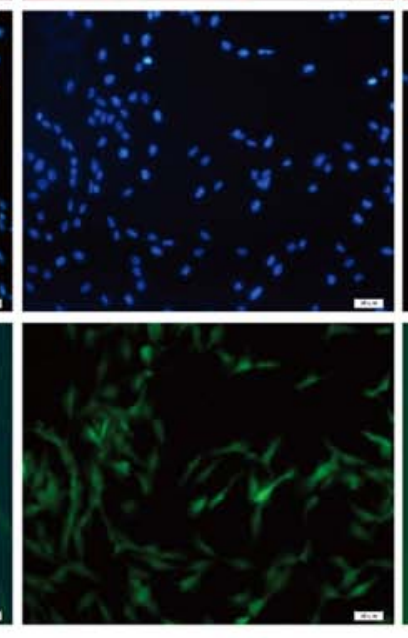

Serum starved for $24 \mathrm{~h}+10 \%$ FBS for $30 \mathrm{~min}$
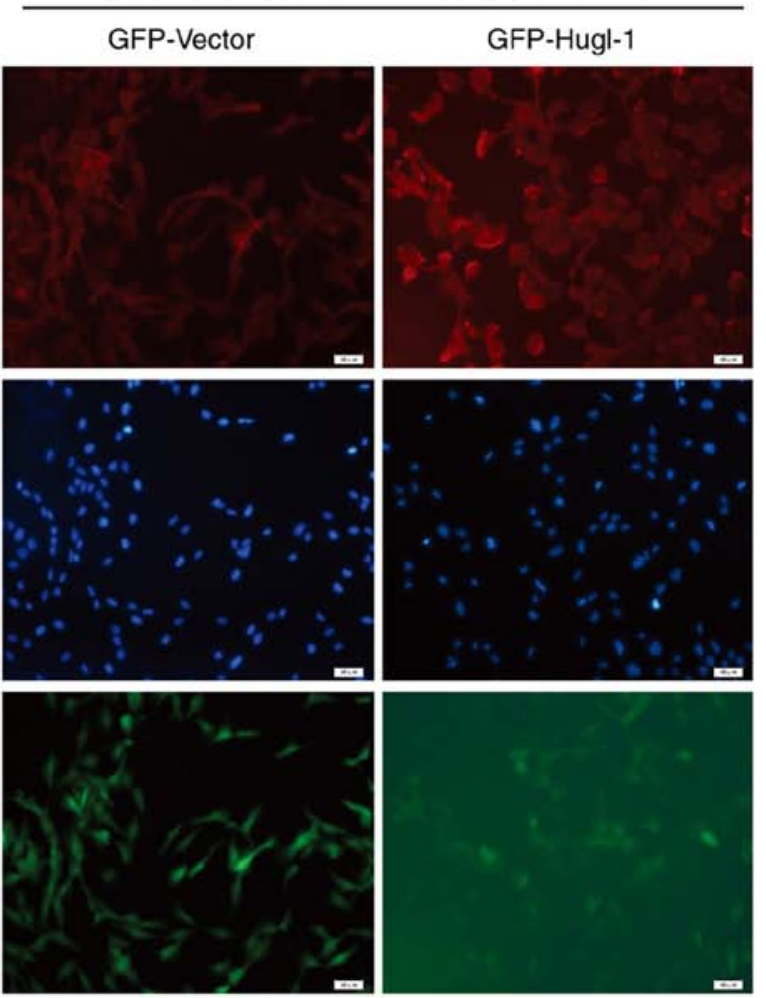

GFP-Hugl-1

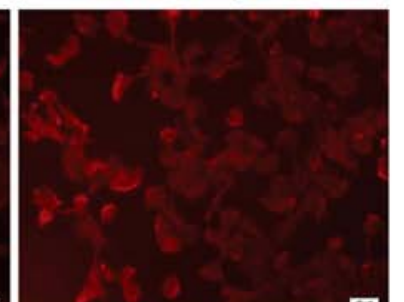

C

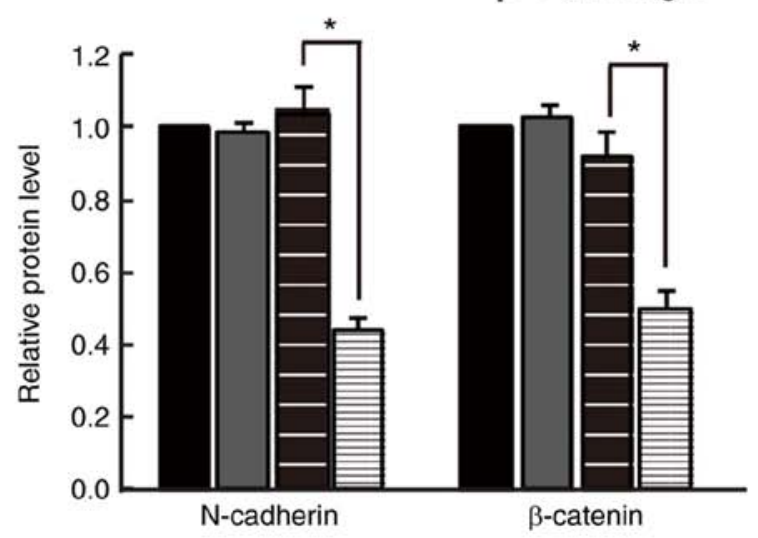

Figure 2. Hugl-1 accelerates cytoskeletal remodeling. (A) Following serum starvation for 24 h, GFP and Hugl-1 overexpressing cells were stimulated with $10 \%$ FBS for $30 \mathrm{~min}$ and stained with conjugated phalloidin (red). The images indicated that more dot or fan-like protrusions were detected at the cell periphery in Hugl-1 overexpressing cells. (B) Western blot analysis was performed to detect the protein expression levels of N-cadherin, $\beta$-catenin and integrin $\beta 1$ in GFP and Hugl-1 overexpressing cells. (C) Quantification results of (B). Scale bar, $50 \mu \mathrm{m}$. ${ }^{*} \mathrm{P}<0.05$. Hugl-1, human giant larvae-1; GFP, green fluorescent protein; FBS, fetal bovine serum.

$\mathrm{N}$-cadherin partially mediates the effects of Hugl-1 expression on glioma cell migration.

\section{Discussion}

Intercellular adhesion plays a crucial role in the maintenance of cell polarity to regulate normal tissue architecture and function $(41,42)$. This process is often disrupted in neoplastic tumors $(43,44)$. Loss of polarity is considered one of the trigger signals for tumorigenesis and invasion of surrounding tissues $(45,46)$. As a cell polarity regulator, Hugl-1 expression is downregulated in several types of human cancer, such as squamous cell lung carcinoma (15), esophageal carcinoma (47), pancreatic carcinoma (16), endometrial cancer (14) and malignant melanoma (12), and is inversely associated with patient prognosis (11-15). We previously demonstrated that Hugl-1 can 
A

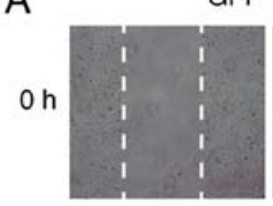

$48 \mathrm{~h}$

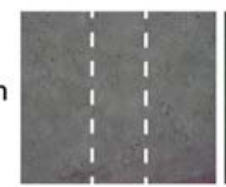

GFP-Vector
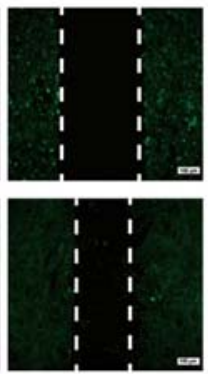
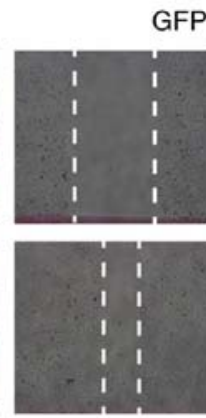

GFP-Hug-1

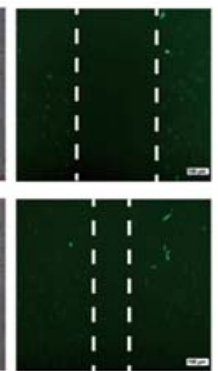

B
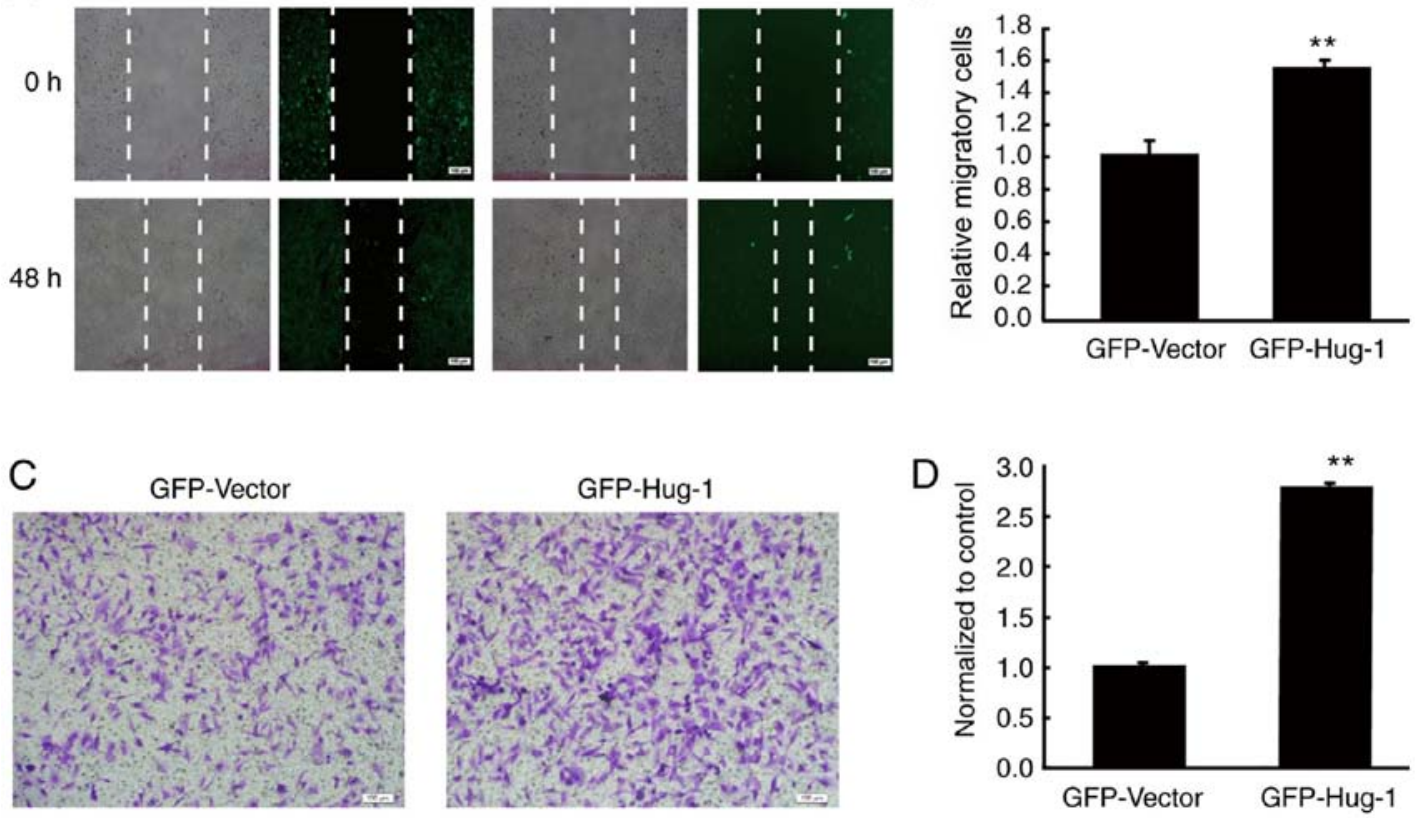

Figure 3. Hugl-1 promotes migration and invasion of glioma cells. (A) Representative digital images of the wound healing assay taken at 0 and $48 \mathrm{~h}$ following scratching. (B) Quantification results of (A). (C) The invasive ability of glioma cells was assessed via the Transwell assay. (D) Quantification results of (C). Scale bar, $100 \mu \mathrm{m}$. ** $\mathrm{P}<0.01$ vs. GFP-Vector. Hugl-1, human giant larvae-1; GFP, green fluorescent protein.

inhibit tumor progression in vivo, while no significant effects on cell proliferation were observed in vitro (17).

The results of the present study demonstrated that overexpression of Hugl-1 decreased cell-cell adhesion, probably by regulating $\mathrm{N}$-cadherin protein expression. In addition, overexpression of Hugl-1 promoted glioma cell migration and invasion. Notably, overexpression or knockdown of $\mathrm{N}$-cadherin partially suppressed or enhanced the induction effect of Hugl-1 expression on glioma cell migration and invasion, respectively. Taken together, these results suggest that Hugl-1 promotes migration and invasion of malignant glioma cells by decreasing N-cadherin expression, thus Hugl-1 may act as a novel therapeutic target in patients with GBM, and function as a marker of GBM prognosis.

Schimanski et al (13) demonstrated that Hugl-1 expression is lost in $75 \%$ of tumor samples and that these deletions are associated with advanced disease stage, particularly with lymph node metastasis. Similarly, loss of Hugl-1 expression in endometrial cancer may contribute to lymph node metastasis (14). Notably, overexpression of wild-type Hugl-1 inhibits HCC migration and invasion (11). Kuphal et al (12) reported that upregulation of Hugl-1 increases cell adhesion and decreases cell migration in malignant melanoma. However, the results of the present study demonstrated that overexpression of Hugl-1 promoted glioma cell migration and invasion. Although Hugl-1 expression decreases in malignant melanoma, HCC and gliomas, it exhibits opposite effects on cell migration and invasion (promotion versus inhibition) in different types of tumors $(11,12,17)$. These differences may be due to the different cell types used in each experiment under specific conditions. Kuphal et al (12) and $\mathrm{Lu}$ et al (11) used Mel Im or SK-HEP-1 cells, which are epithelial cells, while the present study used U251-MG glioma cells, a cell type that belongs to glia-derived cells (48). However, whether the functions of Hugl-1 are cell-type specific remains unknown and should be investigated in prospective studies.

Cell migration and invasion include multiple processes, such as extracellular matrix degradation, cytoskeletal reorganization, de-adhesion and adhesion $(49,50)$. Cytoskeletal reorganization is an important process that affects assembly and disassembly of cell-cell adhesions and leads to morphological and motility changes of tumor cells (50). It is well-known that low expression levels of Hugl-1 in gliomas decrease cell-cell adhesion, promote cell migration and ultimately contribute to cancer cell dissemination and tumor progression (51). However, the results of the present study are not consistent with these conclusions, suggesting that the balance of polar proteins may be the optimum condition for maintaining cell homeostasis (52). In addition, the results of the present study demonstrated that overexpression of Hugl-1 significantly promoted pseudopodia formation and supported the enhanced cell-extracellular matrix adhesion. Asano et al (53) reported that $\mathrm{N}$-cadherin expression is negatively associated with tumor invasion. The results of the present study demonstrated that overexpression of Hugl-1 decreased cell-cell adhesion and increased cell migration, which was consistent with the decreased protein levels of $\mathrm{N}$-cadherin. Recently, Jossin et al (54) reported that LLGL1 directly binds to $\mathrm{N}$-cadherin and is able to promote its internalization, while disrupting the N-cadherin-LLGL1 interaction, which results in cortical heterotopias. The results of the present study are consistent with these findings.

In conclusion, the results of the present study demonstrated that Hugl-1 promoted glioma cell migration and invasion by decreasing $\mathrm{N}$-cadherin expression. Combined with our previous studies, the results presented here provide a novel role for Hugl-1, which includes inhibition of cell proliferation, while promoting cell migration in glioma, suggesting that Hugl-1 

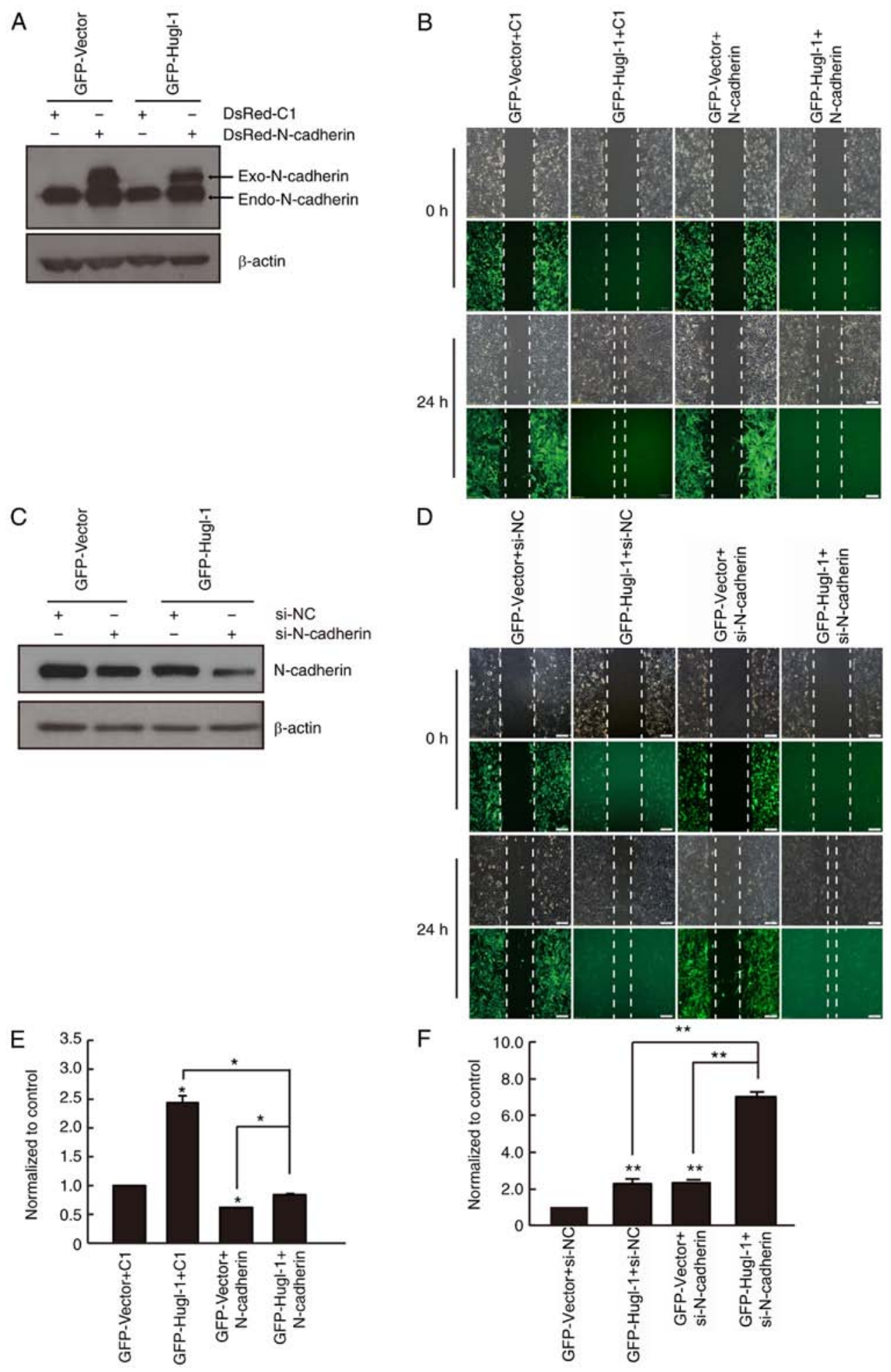

Figure 4. N-cadherin partially mediates the effect of Hugl-1 expression on glioma cell migration. (A) The overexpression efficiency of N-cadherin in U251-MG cells was detected via western blot analysis. (B) The wound healing assay was performed to assess cell migration. (C) The downregulation efficiency of $\mathrm{N}$-cadherin was detected via western blot analysis. (D) The wound healing assay was performed to assess cell migration. (E) Quantification results of (B). (F) Quantification results of (D). Scale bar, $100 \mu \mathrm{m}$. ${ }^{*} \mathrm{P}<0.05,{ }^{* *} \mathrm{P}<0.01$. Hugl-1, human giant larvae-1; GFP, green fluorescent protein; exo, exogenous; endo, endogenous; si, small interfering; $\mathrm{NC}$, negative control.

may play two-sided roles in malignant biological processes. In addition, the results presented here provide useful information for the clinical diagnosis of malignant GBM and the prognosis of patients with GBM. Further studies are required to determine the exact role and precise molecular mechanism of the cell polarity molecule, Hugl-1, for the effective treatment of glioma. Although the present study investigated the role of Hugl-1 in glioma cells, it still presented some limitations. The current experiments were all completed at the cellular level; therefore, there is a lack of detection in animal experiments, which should be further explored in future studies to confirm the present findings. 


\section{Acknowledgements}

Not applicable.

\section{Funding}

The present study was supported by the National Natural Science Foundation of China (grant nos. 81672489, 81872053 and 81902526) and the Postgraduate Research \& Practice Innovation Program of Jiangsu Province (grant no. KYCX20_2460).

\section{Availability of data and materials}

The datasets used and/or analyzed during the current study are available from the corresponding author on reasonable request.

\section{Authors' contributions}

YW wrote the manuscript and contributed to data analysis. YZ, BS and XZ performed the experiments. RY contributed to the study design. $\mathrm{XZ}$ contributed to the study design, reviewed and edited the manuscript. All authors have read and approved the final manuscript.

\section{Ethics approval and consent to participate}

Not applicable.

\section{Patient consent for publication}

Not applicable.

\section{Competing interests}

The authors declare that they have no competing interests.

\section{References}

1. Gould J: Breaking down the epidemiology of brain cancer. Nature 561: S40-S41, 2018.

2. Meyer MA: Malignant gliomas in adults. N Engl J Med 359: 1850,2008

3. Osswald M and Morais-de-Sá E: Dealing with apical-basal polarity and intercellular junctions: A multidimensional challenge for epithelial cell division. Curr Opin Cell Biol 60: 75-83, 2019.

4. Martin-Belmonte F and Perez-Moreno M: Epithelial cell polarity, stem cells and cancer. Nat Rev Cancer 12: 23-38, 2011.

5. Hariharan IK and Bilder D: Regulation of imaginal disc growth by tumor-suppressor genes in Drosophila. Annu Rev Genet 40: 335-361, 2006.

6. Kashyap A, Zimmerman T, Ergül N, Bosserhoff A, Hartman U, Alla V, Bataille F, Galle PR, Strand S and Strand D: The human Lgl polarity gene, Hugl-2, induces MET and suppresses Snail tumorigenesis. Oncogene 32: 1396-1407, 2013.

7. Zimmermann T, Kashyap A, Hartmann U, Otto G, Galle PR, Strand S and Strand D: Cloning and characterization of the promoter of Hugl-2, the human homologue of Drosophila lethal giant larvae (lgl) polarity gene. Biochem Biophys Res Commun 366: 1067-1073, 2008.

8. Grifoni D, Garoia F, Bellosta P, Parisi F, De Biase D, Collina G, Strand D, Cavicchi S and Pession A: aPKCzeta cortical loading is associated with $\mathrm{Lgl}$ cytoplasmic release and tumor growth in Drosophila and human epithelia. Oncogene 26: 5960-5965, 2007.

9. Ohshiro T, Yagami T, Zhang C and Matsuzaki F: Role of cortical tumour-suppressor proteins in asymmetric division of Drosophila neuroblast. Nature 408: 593-596, 2000.
10. Vasioukhin V: Lethal giant puzzle of Lgl. Dev Neurosci 28: 13-24, 2006.

11. Lu X, Feng X, Man X, Yang G, Tang L, Du D, Zhang F, Yuan H, Huang Q, Zhang Z, et al: Aberrant splicing of Hugl-1 is associated with hepatocellular carcinoma progression. Clin Cancer Res 15: 3287-3296, 2009.

12. Kuphal S, Wallner S, Schimanski CC, Bataille F, Hofer P, Strand S, Strand D and Bosserhoff AK: Expression of Hugl-1 is strongly reduced in malignant melanoma. Oncogene 25: 103-110, 2006.

13. Schimanski CC, Schmitz G, Kashyap A, Bosserhoff AK, Bataille F, Schäfer SC, Lehr HA, Berger MR, Galle PR, Strand S and Strand D: Reduced expression of Hugl-1, the human homologue of Drosophila tumour suppressor gene $\operatorname{lgl}$, contributes to progression of colorectal cancer. Oncogene 24: 3100-3109, 2005.

14. Tsuruga T, Nakagawa S, Watanabe M, Takizawa S, Matsumoto Y, Nagasaka K, Sone K, Hiraike H, Miyamoto Y, Hiraike O, et al: Loss of Hugl-1 expression associates with lymph node metastasis in endometrial cancer. Oncol Res 16: 431-435, 2007.

15. Matsuzaki T, Takekoshi S, Toriumi K, Kitatani K, Nitou M, Imamura N, Ogura G, Masuda R, Nakamura N and Iwazaki M: Reduced expression of Hugl 1 contributes to the progression of lung squamous cell carcinoma. Tokai J Exp Clin Med 40: 169-177, 2015.

16. Biesterfeld S, Kauhausen A, Kost C, Gockel I, Schimanski CC and Galle PR: Preservation of HUGL-1 expression as a favourable prognostic factor in pancreatic carcinoma. Anticancer Res 32: 3153-3159, 2012.

17. Liu X, Lu D, Ma P, Liu H, Cao Y, Sang B, Zhu X, Shi Q, Hu J, Yu R and Zhou X: Hugl-1 inhibits glioma cell growth in intracranial model. J Neurooncol 125: 113-121, 2015.

18. Massimi P, Narayan N, Thomas M, Gammoh N, Strand S, Strand D and Banks L: Regulation of the hDlg/hScrib/Hugl-1 tumour suppressor complex. Exp Cell Res 314: 3306-3317, 2008.

19. Zhong XL and Rescorla FJ: Cell surface adhesion molecules and adhesion-initiated signaling: Understanding of anoikis resistance mechanisms and therapeutic opportunities. Cell Signal 24: 393-401, 2012.

20. Fife CM, McCarroll JA and Kavallaris M: Movers and shakers: Cell cytoskeleton in cancer metastasis. Brit J Pharmacol 171: 5507-5523, 2014

21. Gloushankova NA, Rubtsova SN and Zhitnyak IY: Cadherin-mediated cell-cell interactions in normal and cancer cells. Tissue Barriers 5: e1356900, 2017.

22. Pal M, Bhattacharya S, Kalyan G and Hazra S: Cadherin profiling for therapeutic interventions in Epithelial Mesenchymal Transition (EMT) and tumorigenesis. Exp Cell Res 368: 137-146, 2018.

23. Nair KS, Naidoo R and Chetty R: Expression of cell adhesion molecules in oesophageal carcinoma and its prognostic value. J Clin Pathol 58: 343-351, 2005.

24. Huang C, Kratzer MC, Wedlich D and Kashef J: E-cadherin is required for cranial neural crest migration in Xenopus laevis. Dev Biol 411: 159-171, 2016.

25. Bremmer F, Schallenberg S, Jarry H, Küffer S, Kaulfuss S, Burfeind P, Strauß A, Thelen P, Radzun HJ, Ströbel P, et al: Role of N-cadherin in proliferation, migration, and invasion of germ cell tumours. Oncotarget 6: 33426-33437, 2015.

26. Mrozik KM, Blaschuk OW, Cheong CM, Zannettino ACW and Vandyke K: N-cadherin in cancer metastasis, its emerging role in haematological malignancies and potential as a therapeutic target in cancer. BMC Cancer 18: 939, 2018.

27. Camand E, Peglion F, Osmani N, Sanson $M$ and Etienne-Manneville S: N-cadherin expression level modulates integrin-mediated polarity and strongly impacts on the speed and directionality of glial cell migration. J Cell Sci 125: 844-857, 2012.

28. Gheldof A and Berx G: Cadherins and epithelial-to-mesenchymal transition. Prog Mol Biol Transl Sci 116: 317-336, 2013.

29. Kourtidis A, Lu R, Pence LJ and Anastasiadis PZ: A central role for cadherin signaling in cancer. Exp Cell Res 358: 78-85, 2017.

30. Kashima T, Kawaguchi J, Takeshita S, Kuroda M, Takanashi M, Horiuchi H, Imamura T, Ishikawa Y, Ishida T, Mori S, et al: Anomalous cadherin expression in osteosarcoma. Possible relationships to metastasis and morphogenesis. Am J Pathol 155: 1549-1555, 1999

31. Han ZX, Wang XX, Zhang SN, Wu JX, Qian HY, Wen YY, Tian H, Pei DS and Zheng JN: Downregulation of PAK5 inhibits glioma cell migration and invasion potentially through the PAK5-Egr1-MMP2 signaling pathway. Brain Tumor Pathol 31: 234-241, 2014. 
32. Li F, Jin D, Guan L, Zhang CC, Wu T, Wang YJ and Gao DS: CEP55 promoted the migration, invasion and neuroshpere formation of the glioma cell line U251. Neurosci Lett 705: 80-86, 2019.

33. Wang T, Liu Y, Xu XH, Deng CY, Wu KY, Zhu J, Fu XQ, He M and Luo ZG: Lgll activation of rab10 promotes axonal membrane trafficking underlying neuronal polarization. Dev Cell 21: 431-444, 2011.

34. Wicki A, Lehembre F, Wick N, Hantusch B, Kerjaschki D and Christofori G: Tumor invasion in the absence of epithelialmesenchymal transition: Podoplanin-mediated remodeling of the actin cytoskeleton. Cancer Cell 9: 261-272, 2006.

35. Li N, Chen G, Liu J, Xia Y, Chen H, Tang H, Zhang F and Gu N: Effect of surface topography and bioactive properties on early adhesion and growth behavior of mouse preosteoblast MC3T3-E1 cells. ACS Appl Mater Interfaces 6: 17134-17143, 2014.

36. Lewczuk $Ł$, Pryczynicz A and Guzińska-Ustymowicz K: Cell adhesion molecules in endometrial cancer-A systematic review. Adv Med Sci 64: 423-429, 2019.

37. McKeown SJ, Wallace AS and Anderson RB: Expression and function of cell adhesion molecules during neural crest migration. Dev Biol 373: 244-257, 2013.

38. Zhan T, Rindtorff $\mathrm{N}$ and Boutros $\mathrm{M}$ : Wnt signaling in cancer Oncogene 36: 1461-1473, 2017.

39. Taciak B, Pruszynska I, Kiraga L, Bialasek M and Krol M Wnt signaling pathway in development and cancer. J Physio Pharmacol 69, 2018.

40. Li ZH, Zhou Y, Ding YX, Guo QL and Zhao L: Roles of integrin in tumor development and the target inhibitors. Chin J Nat Med 17: 241-251, 2019.

41. Li JC, Cheng LC and Jiang HY: Cell shape and intercellular adhesion regulate mitotic spindle orientation. Mol Biol Cell 30 : 2458-2468, 2019.

42. Mack NA and Georgiou M: The interdependence of the Rho GTPases and apicobasal cell polarity. Small GTPases 5: 10, 2014.

43. Bonastre E, Brambilla E and Sanchez-Cespedes M: Cell adhesion and polarity in squamous cell carcinoma of the lung. J Pathol 238: 606-616, 2016.

44. Waghmare I and Kango-Singh M: Loss of cell adhesion increases tumorigenic potential of polarity deficient scribble mutant cells. PLoS One 11: e0158081, 2016.
45. Wan S, Meyer AS, Weiler SME, Rupp C, Tóth M, Sticht C, Singer S, Thomann S, Roessler S, Schorpp-Kistner M, et al: Cytoplasmic localization of the cell polarity factor scribble supports liver tumor formation and tumor cell invasiveness. Hepatology 67: 1842-1856, 2018.

46. Bhattacharya S: Cell polarity: A link to epithelial-mesenchymal transition and vascular mimicry. Crit Rev Eukar Gene 28: 101-105, 2018.

47. Song J, Peng XL, Ji MY, Ai MH, Zhang JX and Dong WG: Hugl-1 induces apoptosis in esophageal carcinoma cells both in vitro and in vivo. World J Gastroenterol 19: 4127-4136, 2013.

48. Ke LD, Shi YX and Yung WK: VEGF(121), VEGF(165) overexpression enhances tumorigenicity in U251 MG but not in NG-1 glioma cells. Cancer Res 62: 1854-1861, 2002.

49. Painter KJ, Armstrong NJ and Sherratt JA: The impact of adhesion on cellular invasion processes in cancer and development. J Theor Biol 264: 1057-1067, 2010.

50. Cavallaro U and Christofori G: Cell adhesion and signalling by cadherins and Ig-CAMs in cancer. Nat Rev Cancer 4: 118-132, 2004.

51. Grifoni D, Garoia F, Schimanski CC, Schmitz G, Laurenti E, Galle PR, Pession A, Cavicchi S and Strand D: The human protein Hugl-1 substitutes for Drosophila lethal giant larvae tumour suppressor function in vivo. Oncogene 23: 8688-8694, 2004.

52. Yu FX, Zhao B and Guan KL: Hippo pathway in organ size control, tissue homeostasis, and cancer. Cell 163: 811-828, 2015.

53. Asano K, Duntsch CD, Zhou Q, Weimar JD, Bordelon D, Robertson JH and Pourmotabbed T: Correlation of N-cadherin expression in high grade gliomas with tissue invasion. J Neurooncol 70: 3-15, 2004.

54. Jossin Y, Lee M, Klezovitch O, Kon E, Cossard A, Lien WH, Fernandez TE, Cooper JA and Vasioukhin V: Llgll connects cell polarity with cell-cell adhesion in embryonic neural stem cells. Dev Cell 41: 481-495.e5, 2017.

cc) () $\odot$ This work is licensed under a Creative Commons C Attribution-NonCommercial-NoDerivatives 4.0 International (CC BY-NC-ND 4.0) License. 